\title{
LA UNIFICACIÓN DE LA JURISPRUDENCIA EN MATERIA CIVIL Y CONTENCIOSO ADMINISTRATIVO DEL SISTEMA JURÍDICO HONDUREÑO
}

\section{Abog. Jacobo Gutiérrez Sánchez ${ }^{1}$}

$\mathrm{E}$ I nuevo Código Procesal Civil de Honduras introdujo significativos avances; sin embargo, por un lado, desapareció como causal de casación la infracción a la doctrina legal y, por otro, manifiesta que la casación tiene como fin la unificación de la jurisprudencia nacional, generando la pregunta de cómo se puede unificar la jurisprudencia sin existir doctrina legal. Esta reforma no solo perjudica la unificación de la jurisprudencia civil, sino también la jurisprudencia contenciosa-administrativa, ya que se le aplica supletoriamente el Código Procesal Civil en lo relacionado al recurso de casación. En vista de lo anterior, el Congreso Nacional debe realizar una reforma al artículo 716, numeral 2) del Código Procesal Civil, añadiendo que se puede interponer el recurso de casación "por infracción de doctrina legal en la parte dispositiva de la sentencia". De esta manera, sería posible unificar la jurisprudencia en la materia civil $\mathrm{y}$, consecuentemente, en la materia contencioso-administrativa.

Todos los autores están de acuerdo en que el tema de las "fuentes del Derecho" pertenece a la Teoría General del Derecho (Orellana, 2013); sin embargo dichos autores, logrado establecer una diferencia sustancial entre las distintas fuentes del derecho. El vocablo "fuente" deriva del latín "fono, frontis, fundo", que significa "provenir, derramar". Así, desde el punto de visto etimológico, se indaga "de dónde emerge o surge el derecho" (Ricardo, 2015).

García Maynez y Luis Olaso, estructuran la siguiente clasificación de fuentes (Mila, 2012):

a. Históricas: se refieren a los documentos en los cuales están consignados los preceptos del Derecho positivo, documentos - no en sentido jurídico - sino histórico, es decir: Folios, piedra, papiros, leyendas, gestas, entre otras.

b. Reales o materiales: Vienen a ser los factores económicos, sociales, políticos, religiosos y otros, que determinan el contenido de las formales.

c. Formales: entendidas como a) el órgano que las genera, b) el proceso de elaboración, y) el producto que resulta.

Las fuentes formales son instrumentales, pues a través de ellas se pretende saber cuándo y en qué condiciones una norma jurídica es válida y obligatoria para una sociedad determinada. (Castro, Introducción al estudio del derecho, 2010). Se reconocen como fuentes formales del derecho la ley, la costumbre, la jurisprudencia, la doctrina y los principios generales del derecho.

Eduardo García Maynez (Maynez, 2004) menciona que la palabra jurisprudencia posee dos acepciones:

1. Ciencia del derecho o teoría del orden jurídico positivo.

2. Conjunto de principios y doctrinas contenidas en las decisiones de los tribunales.

Fecha de Recepción: 01 de noviembre del 2017

Fecha de Aceptación: 01 de diciembre del 2017

1 Abogado Independiente, graduado de la Universidad Nacional Autónoma de Honduras (UNAH),

E-mail: gsjacobo@yahoo.com 
Asimismo, él divide la jurisprudencia en obligatoria y no obligatoria (Máynez, 2004). Sobre la obligatoriedad de la jurisprudencia el Dr. Leonel Pereznieto Castro manifiesta: "La obligatoriedad de la jurisprudencia varía de acuerdo con el sistema jurídico de que se trate. Así, por ejemplo en sistemas jurídicos como el mexicano, el salvadoreño o el colombiano, sistemas llamados escritos o de derechos codificados, la ley es la fuente de creación normativa más importante y la jurisprudencia suele ser obligatoria, pero su obligatoriedad es relativizada, según el sistema, al requerir un cierto número de decisiones sobre el mismo punto controvertido y en el mismo sentido, lo cual provoca que su formación sea excesivamente lenta.

En el caso de sistemas jurídicos como el inglés o el estadounidense, llamados sistemas de derecho consuetudinario o de common law, la jurisprudencia es la fuente principal de creación normativa, ya que en esos sistemas se asigna a los jueces el papel más importante en este ámbito. La ley es fuente secundaria, al menos para los jueces, quienes consultan las decisiones previas de otros jueces. Estos criterios son retomados y la referencia a las escasa leyes existentes no es el esfuerzo principal." (Castro, Introducción al estudio del derecho, 2010)

El sistema seguido por el derecho hondureño es de derecho escrito o codificado, por tanto, la ley es la fuente principal del derecho y, en nuestro país, tomando la segunda acepción de jurisprudencia, se ha entendido esta como "la interpretación que de la ley hace la Corte Suprema de Justicia cuando la aplica a tres casos concreto sometidos a ella y la generaliza." (Valencia, 2013). Lo que el Dr. García Maynez y el Dr. Castro llaman jurisprudencia obligatoria equivale a lo que en el derecho hondureño se denomina "doctrina legal", mientras que la jurisprudencia no obligatoria se refiere a los demás fallos de los órganos jurisdiccionales supremos. Así, no toda jurisprudencia constituye doctrina legal, es decir, no toda jurisprudencia es obligatoria.

La implementación de la doctrina legal en un sistema jurídico como fuente del derecho, contribuye al cumplimiento del principio de igualdad y a la seguridad y certidumbre jurídicas. Además de esto, la jurisprudencia viene a salvar imperfecciones de la ley, ya sean estas vacíos o deficiente redacción por parte del legislador (Castro, Introducción al estudio del derecho, 2010).

Los países pueden determinar lo que para ellos debe entenderse por jurisprudencia obligatoria. Por ejemplo en Colombia, está consagrada en el artículo 10 de la Ley 153 de 1887, modificado por la Ley 169 de 1989, artículo $4^{\circ}$, que dispone: "Tres decisiones uniformes dadas por la Corte Suprema, como tribunal de casación sobre un mismo punto de derecho, constituyen doctrina probable, y los jueces podrán aplicarla en casos análogos, lo cual no obsta para que la Corte varíe la doctrina en caso que juzgue erróneas las decisiones anteriores". En los Estados Unidos Mexicanos, en el artículo 222 de su Ley de Amparo dice: “La jurisprudencia por reiteración del pleno de la Suprema Corte de Justicia de la Nación se establece cuando se sustente un mismo criterio en cinco sentencias no interrumpidas por otra en contrario, resueltas en diferentes sesiones, por una mayoría de cuando menos ocho votos." Vemos así que en ambos países se utilizan distintos términos para referirse al mismo contenido, este es, sentencias con carácter obligatorio.

Se puede apreciar que dentro de los cuerpos legales de Honduras se define la doctrina legal de la siguiente manera:

a. El Código Procesal Penal de 1985, en su artículo 360, expresa: “Casación por infracción de ley o de doctrina legal. Habrá lugar al recurso de casación por infracción de ley o de doctrina legal, cuando dados los hechos que se declaren probados en la sentencia, se haya infringido un precepto penal u otra norma jurídica de carácter sustantivo, que deba ser observada para la aplicación de la ley penal o un principio de doctrina legal también de carácter sustantivo. 
Se entenderá por doctrina legal la reconocida como tal por la Corte Suprema de Justicia, por medio de tres (3) sentencias conformes sobre un mismo asunto..."; y,

b. La Ley sobre Justicia Constitucional del año 2003, en su artículo 73, menciona: “DE LA DOCTRINA LEGAL EN EL AMPARO. Tres sentencias conformes dictadas por la Corte Suprema de Justicia a través de la Sala de lo Constitucional en las demandas de amparo, constituyen doctrina legal. Sin embargo, la Sala de lo Constitucional, podrá separarse de su propia doctrina, razonando la innovación."

¿Qué ha pasado en la materia civil y contencioso administrativo? El Código de Procedimientos Comunes de 1906, establecía en su artículo 902, numeral 1, que el recurso de casación podía fundarse, entre otras causas, en la infracción de ley o doctrina legal en la parte dispositiva de la sentencia. Así, al entrar en vigencia la Ley de la Jurisdicción de lo Contencioso Administrativo en 1987, se aplicaba supletoriamente ${ }^{2}$ Io referente al recurso de casación del Código Procedimientos de 1906, es decir, existía en materia contencioso administrativo como causal de casación la infracción de ley o doctrina legal en la parte dispositiva de la sentencia.

Con la implementación del nuevo Código Procesal Civil (CPC) en el año 2010, desaparece, por un lado, como causal de casación la infracción a la doctrina legal y, por otro, manifiesta que la casación tiene como fin la unificación de la jurisprudencia nacional. El artículo 716 del CPC establece: "FINES DE LA CASACIÓN.

1. El recurso de casación tiene como fines la protección de las normas del ordenamiento jurídico, procurando y promoviendo la más adecuada aplicación e interpretación del derecho objetivo, así como la unificación de la jurisprudencia nacional.

2. Las normas sobre recurso de casación deberán aplicarse e interpretarse en la forma más favorable a la finalidad de unificación de la jurisprudencia como instrumento de garantía de la igualdad de todos ante la ley, y de la seguridad y certidumbre jurídicas."

El artículo 719 del CPC que enumera las causales de casación, dice: "CAUSALES DEL RECURSO.

1. Se podrá impugnar la aplicación e interpretación de las normas procesales que regulan:

a. La jurisdicción, competencia, genérica, objetiva, funcional, y adecuación de procedimiento.

b. Los actos y garantías procesales cuando su infracción suponga la nulidad o produjera indefensión.

c. La forma y contenido de la sentencia.

2. Igualmente, se podrá impugnar la aplicación e interpretación de las normas de derecho empleadas para la solución de fondo del litigio."

De la lectura de los artículos citados, surge la pregunta de cómo se puede unificar la jurisprudencia sin existir como causal de casación la infracción a la doctrina legal en la parte dispositiva de la sentencia. Así, resulta difícil unificar la jurisprudencia en materia civil y, consecuentemente, en la materia contencioso administrativo.

2 Artículo 134 de la Ley de la Jurisdicción de lo Contencioso Administrativo. 
Por otro lado, la redacción del artículo 716 del CPC permite la interpretación de que la Sala de lo Civil y la Sala de lo Contencioso Administrativo pueden resolver el recurso de casación simplemente considerando una sola sentencia anterior dictada por el mismo órgano, lo que crea incertidumbre jurídica.

En la práctica, los profesionales del derecho al interponer el recurso de casación no pueden invocar como causal de casación "la infracción de doctrina legal en la parte dispositiva de la sentencia". Lo que pueden realizar es un apartado en el escrito de casación explicando cómo la sentencia recurrida se aparta de la línea jurisprudencial de la sala respectiva, pero este apartado no vincula al juez a decidir en ese sentido, ni es una formalidad exigida.

Por tanto, el medio para que se puede unificar la jurisprudencia en materia civil y contencioso administrativo es que el Congreso Nacional, haciendo uso de sus atribuciones constitucionales, realice una reforma al artículo 716, numeral 2) del Código Procesal Civil, estableciendo que se puede interponer el recurso de casación, expresando como causal "la infracción de doctrina legal en la parte dispositiva de la sentencia." De esta manera, sería posible unificar la jurisprudencia en la materia civil y en la materia contencioso-administrativa, contribuyendo al cumplimiento del principio de igualdad y a la seguridad y certidumbre jurídicas.

\section{BIBLIOGRAFÍA}

- $\quad$ Castro, L. P. (2010). Introducción al estudio del derecho. México: Oxford University Press México, S.A. de C.V.

- $\quad$ Castro, L. P. (2010). Introducción al estudio del derecho (Sexta ed.). Oxford University Press México, S.A. de C.V.

- $\quad$ Castro, L. P. (2010). Introducción al estudio del derecho (Sexta ed.). México: Oxford University Press México, S.A. de C.V.

- $\quad$ Maynez, E. G. (2004). Introducción al estudio del derecho (57a. ed.). Editorial Porrúa.

- Máynez, E. G. (2004). Introducción al estudio del derecho. (57a. ed.). Editorial Porrúa.

- $\quad$ Mila, F. (2012). Manual de introducción al Derecho: un texto ajustado a las tendencias modernas del Derecho. Vadell Hermanos Editores, C.A.

- Orellana, E. (2013). Curso de Derecho Administrativo, Tomo I (Quinta ed.). Tegucigalpa, Honduras.

- $\quad$ Ricardo, A. P. (2015). Derecho 1 (Segunda ed.). Grupo Editorial Patria.

- $\quad$ Solano, V. E. (2017). La jurisprudencia como fuente del derecho: el caso de Costa Rica. Revista Judicial, 225.

- Valencia, G. A. (2013). Introducción a la Interpretación y Aplicación al Derecho hondureño. Tegucigalpa: OIM Editorial S.A. de C.V. 